\title{
THERMODYNAMIC TESTS WITH NANO-CERAMIC THERMAL INSULATION COATINGS
}

\author{
David BOZSAKY \\ Department of Architecture and Building Construction, Faculty of Architecture \\ Civil Engineering and Transport Sciences, Széchenyi István University \\ Egyetem tér 1, H-9026 Győr, Hungary, e-mail: bozsaky@gmail.com
}

Received 6 June 2016; accepted 28 August 2016

\begin{abstract}
From nanotechnology-based thermal insulation materials nano-ceramic thermal insulation coatings are generally considered to be the most critical because of contradictory technical data that could be founded in special literature. Complete agreement had not been already found about the mechanism how does their insulating effect take. In the Laboratory of Building Materials and Building Physics at Széchenyi István University (Györ, Hungary) several thermodynamic tests were made in order to find out thermodynamic process inside this material. Several building structures with different order of layers were tested with heat flow meter. Results showed that convective heat transfer coefficient cannot be taken account in usual way using this material as thermal insulation.
\end{abstract}

Keywords: Nanotechnology, Nano-ceramics, Thermal insulation, Thermodynamics

\section{Introduction}

Nano (symbol: $\mathrm{n}$ ) is an SI prefix meaning one billionth. In the metric system this prefix indicates a factor of $10^{-9}$. Nanotechnology is science, engineering, and technology conducted on nano-scale, which is about 1-100 nanometers. These extremely small things can be used across several science fields like chemistry, biology, physics, materials science, and engineering. Traditionally it means building things from the bottom up, with atomic precision [1], [2].

The first basic concept of nanotechnology was presented by Richard P. Feynman (1918-1988) at the California Institute of Technology (California, USA) on 29th December, 1959. He described the possibility of synthesis via the direct manipulation of 
atoms [3]. The term 'nanotechnology' was first used by Norio Taniguchi (1912-1999) in 1974, though it was not widely known [3], [4]. The first fundamental studies about nanotechnology were written by Claes-Göran Granqvist (1946-) and Robert A. Buhrman (1944-) in 1976 [2].

This term was not used again until 1981 when Kim Eric Drexler (1955-) published his first paper on nanotechnology. A more accurate definition of nanotechnology was created by him, as well as the production with dimensions and precision between 0.1 and $100 \mathrm{~nm}$ [3]. Drexler popularized his concept and founded the field of molecular nanotechnology [4].

In the 1980s two major breakthroughs came to help the development of nanotechnology. In 1981 Gerd Binning (1947-) and Heinrich Rohrer (1933-2013) invented Scanning Tunneling Microscope (STM) at the IBM Zurich Research Laboratory. It provided the visualization of individual atoms and bonds and was successfully used to manipulate individual atoms. The second invention, fullerenes (Buckminsterfullerene: C60), were discovered in 1985 by Harold Walter Kroto (19392016), Richard Errett Smalley (1943-2005), and Robert Floyd Curl (1933-) at Rice University [5].

\section{Nanotechnology-based thermal insulation materials in architecture}

The use of nanotechnology is also possible in civil engineering and architecture. Nano-silica additives in cement-based materials can increase durability and compressive strength [3]. They can be used to increase fluidity or water permeability of concrete [6], [7]. Adding nanotubes or nano-fibers, tensile and bending strength of concrete structures can be enhanced [3], [7]. Wood-based products composed with nanotubes or nano-fibers are twice as strong as steel [3]. Coatings containing nanoparticle form of titanium dioxide $\left(\mathrm{TiO}_{2}\right)$ is used to create self-cleaning surfaces [3], [7]. Nanoparticlebased coatings can also provide better adhesion, transparency, corrosion and fire protection [3], [8], [9].

In the 1990s several nanotechnology-based thermal insulation materials appeared on the market and they had continuously increased in the building industry, e.g., expanded polystyrene products including graphite powder additive (e.g., EPS Graphite); vacuum insulation panels; aerogel insulations and nano-ceramic thermal insulation coatings.

Nanotechnology-based thermal insulation materials are generally considered to have better thermal insulation quality than traditional materials. There are three ways of heat transport in traditional thermal insulation materials: thermal conduction (vibration of molecules inside cellular walls), heat flux (between air particles enclosed in cells) and thermal radiation (between opposing cellular walls) [10]. There is also convective and conductive heat transfer between air particles and in a complete construction there is an additional convective heat transfer between air and building structure.

In nanotechnology-based thermal insulation materials one or more ways of heat transport is hampered. This is why they can decrease the heat transfer coefficient of building structures. The well-known formula of heat transfer coefficient is the following: 


$$
U=\frac{1}{\frac{1}{h_{i}}+\sum_{i=1}^{n} \frac{d_{i}}{\lambda_{i}}+\frac{1}{h_{e}}}
$$

In the formula $U$ is the heat transfer coefficient $\left[\mathrm{W} / \mathrm{m}^{2} \mathrm{~K}\right] ; n$ is the number of different layers inside the building structure; $d_{i}$ is the individual thickness of each structural layer $[\mathrm{m}] ; \lambda_{i}$ is the individual thermal conductivity of each structural layer $[\mathrm{W} / \mathrm{mK}] ; h_{i}$ is the internal convective heat transfer coefficient $\left[\mathrm{W} / \mathrm{m}^{2} \mathrm{~K}\right]$; and $h_{e}$ is the external convective heat transfer coefficient $\left[\mathrm{W} / \mathrm{m}^{2} \mathrm{~K}\right]$.

This U-value can be decreased in two ways by nanotechnology-based materials. Some of them (e.g., EPS Graphite, aerogel insulations, and vacuum insulation panels) have a lower thermal conductivity than traditional materials, because the ways of heat transport is blocked inside them. In EPS Graphite products only thermal radiation is slowed down. In vacuum insulation panels thermal conduction and heat flux are also balked. In aerogel insulations all three ways of heat transport are blocked [8], [9].

However, nano-ceramic thermal insulation coatings are generally considered to be the most critical because of the contradictory technical data about their thermal insulating mechanism that could be founded in producers' handouts and also in special literature. Complete agreement had not been already found about the mechanism how their insulating effect is formed. Producers state that their excellent thermal insulating quality is due to their extremely low thermal conductivity [11], [12], [13], [14]. Other researchers claim that thermal insulation coatings can highly increase heat transfer resistance of the insulated surface by reducing convective heat transfer coefficient. Heat energy is not able to transfer in the same way between air and the insulated surface. This process faces with obstacles in the nanostructure and transmission takes much more time [15].

\section{Nano-ceramic thermal insulation coatings}

In the early 1980s, Sridhar Komarneni and Rustum Roy developed the first method of synthetizing nano-ceramics. This process called 'sol-gel' and enabled researchers to test the properties of nano-ceramics [16]. To produce nano-ceramics at a more efficient way this process was later replaced by microwave sintering.

The most common paint-on insulation products in Hungary are Thermo-Shield, Protektor, MANTI and TSM Ceramics. They contain microscopic vacuum-hollow cellular ceramic microspheres with a diameter of 20-120 $\mu \mathrm{m}$. They were made of melted glass or ceramic on high gas-pressure and high temperature $\left(1500^{\circ} \mathrm{C}\right)$. After they cool down, the pressure ends, leaving a vacuum inside the microspheres. Their binding material is a mixture of synthetic rubber and other polymers. The main components are styrene $(20 \%)$ and acryl latex $(80 \%)$. Styrene guarantees the mechanical strength. Acryl latex makes this material resistant against weather conditions and provides adequate flexibility. Other environmental additives (biocides, anti-fouling and antifungal materials) make the final product durable and mold-proofed [15]. 
These coatings are typically used for exterior and interior wall insulation, but they are also suitable for pipe insulation and protection against fire and corrosion. They can be easily transmitted to hard-to-reach sites. Their most important advantage is that they can be applied in places where it is not possible to use thick thermal insulating panels (e.g. scheduled national monuments).

After mixing the ceramic microspheres with the binding material, additives and water, a brush, roller or airless spray can be used to apply on the surface to be insulated [11], [12], [13], [14]. To assure adequate and uniform coverage, spray and roll techniques are recommended. Each coat should be sprayed in the same direction to avoid showing undulations and other imperfections on the wall. Very small areas may be brushed. White and any custom colors are available, but darker colors give a correspondingly lower degree of reflectivity [13].

All surfaces must be clean and free from laitance, dust, dirt, rust, oil or grease before painting. Surfaces must be cleaned to remove any loose or chipping paint or other foreign material. No primer layer is usually required, but it is recommended over gypsum board. Generally two layers of nano-ceramic thermal insulation coating are required, the first of which acts as a primer layer. When the coating is applied by brush, three cross-brushed coats are required for adequate insulation. The drying time of a layer depends on the temperature (at $20^{\circ} \mathrm{C}$, it takes $4-5$ hours). The complete solidification takes 72 hours [13], [14].

\section{Thermodynamic experiments}

The special literature provides different technical details about these materials (Table I). Moreover, thermodynamic details are extraordinarily contradictory [17], [18]. Some sources say that their thermal conductivity is around $0.001-0.003 \mathrm{~W} / \mathrm{mK}$ based on measurements of university laboratories in Latvia, Russia (Volgograd) and Hungary (Debrecen) [11], [12], [13], [14]. Other sources publish much higher values (from $0.014 \mathrm{~W} / \mathrm{mK}$ to $0.140 \mathrm{~W} / \mathrm{mK}$ ) [8], [9], [15] and more correctly talk about their effective thermal conductivity [15] which contains the convective heat transfer coefficient $\left(h_{i}\right.$ and $h_{e}$ ). These details are often not confirmed by documented laboratory tests or refer to insufficiently introduced experiments. They indirectly calculate thermal conductivity of nano-ceramic coating from heat transfer coefficient ( $U$-value) of wall structures according to EN 1934:2000 and EN ISO 8990:2000. EN 1934:2000 is only suitable for determining heat transfer coefficient of a global building structure. EN ISO 8990:2000 is suitable for calculating convective heat transfer coefficient $\left(h_{e}\right.$ and $\left.h_{i}\right)$ [19]. Even so sources take account of the standardized heat transmission coefficients on the inner and outer sides of a wall structure. Each method has the problem that it tries to determine thermal conductivity by an indirect way using conventional data and calculation and it does not take in account that physical and chemical processes inside structures in range from 1 to 100 nanometers can occur differently than in traditional macro sizes.

To directly measure thermal conductivity of a thermal insulation material the only suitable standard is EN 12667:2001 [20].

Additional issues could be raised knowing the measurement results about thermodynamic properties of nano-ceramic coatings investigating energy balance in 
periods of heating and also in the summer. In order to test their thermal performance at external building surfaces dynamic outdoor testing was used. Two comparative coatings and a reference standard facing coating were used. Measured data demonstrated that the representative coating consisting of hollow ceramic microspheres have the same thermodynamic properties as a standard facing coating [21], [22].

Spectral emissivity properties of nano-ceramic thermal insulation coatings were also measured with standard infrared spectroscopy. Measured data demonstrated that coatings have the same radiant properties as standard building coatings [23].

\section{Table I}

Main material properties of nano-ceramic thermal insulation coatings based on the producers' handouts and the special literature [11], [12], [13], [14], [15]

\begin{tabular}{|l|c|c|c|}
\hline Material characteristics & Symbol & Dimension & Value \\
\hline Density (wet) & $\rho_{\text {wet }}$ & $\mathrm{kg} / \mathrm{m}^{3}$ & $500-745$ \\
Density (dry) & $\rho_{d r y}$ & $\mathrm{~kg} / \mathrm{m}^{3}$ & $290-410$ \\
Tensile strength & $\sigma_{t}$ & $\mathrm{kPa}$ & $300-400$ \\
Adhesion strength (concrete) & $\sigma_{a d}$ & $\mathrm{kPa}$ & $460-920$ \\
Adhesion strength (steel) & $\sigma_{a d}$ & $\mathrm{kPa}$ & $470-900$ \\
Liquid water permeability & $w$ & $\mathrm{~kg} / \mathrm{m}^{2} \mathrm{~h}^{0.5}$ & $0.16-0.20$ \\
Thermal conductivity & $\lambda$ & $\mathrm{W} / \mathrm{mK}$ & $0.001-0.003$, or 0.014, \\
& & & or 0.140 \\
\hline
\end{tabular}

\subsection{Experiment 1}

After studying the special literature two experiments were made in the Laboratory of Building Materials and Building Physics at Széchenyi István University (Győr, Hungary) in 2014-2015. Results of Experiment 1 and Experiment 2 were published in 2015 [24], [25] but it is important to summarize them because they were bases of Experiment 3 which can be explained more easily.

In Experiment 1 three different kinds of conventional thermal insulation materials were chosen: Expanded PolyStyrene (EPS), eXtruded PolyStyrene (XPS) and Oriented Strand Boards (OSB). From these materials 5 types (Type 1-5) of samples were made. Sample Type 1 was uncoated and homogeneous so it was used as benchmark. Sample Types 2-5 were sprayed with one-sided or two-sided, 1 and $2 \mathrm{~mm}$ thick nano-ceramic coating. Samples were prepared by the manufacturing company that provided only approximate data about the raw material. The composition is patented and manufacturers generally do not give completely accurate details about the product. It could be definitely stated that the examined coating was outside façade insulation. Wide limits $(20-50 \mathrm{~m} / \mathrm{m} \%)$ were given about the ratio of the binder material, but certainly it neared the lower limit because coating was sprayed on the surface of samples and low ratio of binder material is ideal for spray technology.

According to EN 12667:2001 standard Taurus TCA 300 heat flow meter was used to measure thermal conductivity. Each sample was tested 3 times. Results seemed to show 
a minor increasing effect of nano-ceramic coating to thermal insulation quality. Because sprayed samples (Tpye 2-5) were inhomogeneous materials only their effective thermal conductivity $\left(\lambda_{e f f}\right)$ was comparable with the thermal conductivity of homogeneous samples (Type 1) [26]. Effective thermal conductivity was 1-4\% higher. It is wellknown that the accuracy of Taurus TCA heat flow meter is up to $5 \%$ and these results might be fluctuations in measurement limits. However, in fact, in $87 \%$ there were no deviation between 3 test results of an individual sample, and in 13\% the difference was only $\pm 0.0002 \mathrm{~W} / \mathrm{mK}$ which means really $0.1-0.3 \%$ accuracy. Only XPS samples showed lower values but the decrease of was not as significant as expected (from $0.91 \%$ to $3.32 \%$ ). This reduction can be explained by the sample surface which was not smooth but rough. Small air gaps closed between the measuring panel of the instrument and the specimen. This is why not only thermal conduction occurred but also a minor effect of an additional thermal convection was perceived.

\subsection{Experiment 2}

After analyzing the former results Experiment 2 was conducted. On basis of Experiment 1 an idea came if thermal conductivity of nano-ceramic coating could be measureable directly according to EN 12667:2001. Nevertheless, Taurus TCA 300 heat flow meter can only measure with reliable accuracy (theoretically 5\%) samples with a minimum thickness of $20 \mathrm{~mm}$ and the practical thickness of this material is only 1-2 $\mathrm{mm}$. Moreover reliable measuring limits of this machine are between $0.01-0.50 \mathrm{~W} / \mathrm{mK}$. For these experiments 3 samples of pure nano-ceramic coating were required with a minimum thickness of $20 \mathrm{~mm}$. Each sample was measured 3 times and the average thermal conductivity in air-dry condition was $0.0690 \mathrm{~W} / \mathrm{mK}$ [24].

However, it should be added that nano-ceramic coatings are practically not used with a thickness of $20 \mathrm{~mm}$. Generally they are applied as a thin membrane with a thickness of 0.2 to $2.0 \mathrm{~mm}$. It is also known that thickness could have increasing effect on thermal conductivity of some materials (e.g. EPS, XPS). Therefore it could not be clearly declared that thermal conductivity of this material has the same value of $0.0690 \mathrm{~W} / \mathrm{mK}$ if it is used as a very thin membrane. Unfortunately, there is no way to measure thermal conductivity in case of material thickness as thin as $2.0 \mathrm{~mm}$. This is why thermal conductivity cannot be measured with standardized method on samples with practically used thickness.

\subsection{Experiment 3}

Based on the previous two experiments it could be concluded that insulating effect of nano-ceramic thermal insulation coatings is probably not caused by their extremely low thermal conductivity. As it was formerly mentioned, some sources claim that insulating effect of these materials is generated by not their extremely low thermal conductivity (this value is estimated to be $0.014 \mathrm{~W} / \mathrm{mK}$ ) but their high surface heat transfer resistance.

Considering it as a basic concept a third experiment was conducted in 2016. For these experiments 12 different order of layers were constructed from 300x300 mm samples of Thermal Insulation Materials (TIM) with different thickness. Moreover, 
100x100 mm Air Gap (AG) with a thickness of 20 and $30 \mathrm{~mm}$ included into the construction. There were configurations (Table II), which contained Nano-Ceramic Coated (NCC) and uncoated samples as well (Type 1-12).

Table II

Types of sample configurations for Experiment 3

\begin{tabular}{|l|l}
\hline Type 1 & $20 \mathrm{~mm} \mathrm{AG}+\mathrm{TIM}$ \\
Type 2 & $20 \mathrm{~mm} \mathrm{AG}+2 \mathrm{~mm} \mathrm{NCC}+\mathrm{TIM}$ \\
Type 3 & $30 \mathrm{~mm} \mathrm{AG}+\mathrm{TIM}$ \\
Type 4 & $30 \mathrm{~mm} \mathrm{AG}+2 \mathrm{~mm} \mathrm{NCC}+\mathrm{TIM}$ \\
Type 5 & $\mathrm{TIM}+20 \mathrm{~mm} \mathrm{AG}+\mathrm{TIM}$ \\
Type 6 & $\mathrm{TIM}+2 \mathrm{~mm} \mathrm{NCC}+20 \mathrm{~mm} \mathrm{AG}+\mathrm{TIM}$ \\
Type 7 & $\mathrm{TIM}+30 \mathrm{~mm} \mathrm{AG}+\mathrm{TIM}$ \\
Type 8 & $\mathrm{TIM}+2 \mathrm{~mm} \mathrm{NCC}+30 \mathrm{~mm} \mathrm{AG}+\mathrm{TIM}$ \\
Type 9 & $20 \mathrm{~mm} \mathrm{AG}+\mathrm{TIM}+20 \mathrm{~mm} \mathrm{AG}$ \\
Type 10 & $20 \mathrm{~mm} \mathrm{AG}+2 \mathrm{~mm} \mathrm{NCC}+\mathrm{TIM}+2 \mathrm{~mm} \mathrm{NCC}+20 \mathrm{~mm} \mathrm{AG}$ \\
Type 11 & $30 \mathrm{~mm} \mathrm{AG}+\mathrm{TIM}+30 \mathrm{~mm} \mathrm{AG}$ \\
Type 12 & $30 \mathrm{~mm} \mathrm{AG}+2 \mathrm{~mm} \mathrm{NCC}+\mathrm{TIM}+2 \mathrm{~mm} \mathrm{NCC}+30 \mathrm{~mm} \mathrm{AG}$ \\
\hline
\end{tabular}

Measurements were carried out by the same heat flow meter. Effective thermal conductivity of 3-3 pieces from each type of configurations was measured using 3 different kinds of thermal insulation materials: EPS, XPS and OSB plates. Each sample was measured 3 times. Moreover, sample Types 1-8 were measured in two ways; firstly NCC was on the warm side; secondly NCC was on the cold side. Eventually a total number of 192 different measurements were conducted.

Because of the inhomogeneous, multi-layer structure heat flow meter was able to determine effective thermal conductivity. The experiment was to provide information about thermal insulation ability of nano-ceramic coating this is why the only difference between coated and uncoated samples was the coating itself. Therefore, the main focus of experiments was the difference in effective thermal conductivity between coated and uncoated samples.

All of the samples contained air gap, the effect of convection and conduction inside it was included by the $\lambda_{\text {eff }}$ value. Air gap has the same position and the same size in each sample so the conduction and convection inside air gap should be also the same in each case. This is why difference between effective thermal conductivity of coated and uncoated samples could be attributed only to the nano-ceramic coating.

Assuming that thermal insulation quality of nano-ceramic thermal insulation coatings lies in their high surface heat transfer resistance experiments should show a significant difference between coated and uncoated samples. This difference was reflected by EPS and XPS samples; however, its rate was not as significant as expected.

Just like in Experiment 1 and Experiment 2 in 84\% there were no deviation between 3 test results of an individual sample and in $16 \%$ the difference was only 
$\pm 0.0002 \mathrm{~W} / \mathrm{mK}$ which means also $0.1-0.4 \%$ accuracy instead of the theoretically $5 \%$ accuracy of the heat flow instrument. Therefore, the resulted changes in effective thermal conductivity could be considered to be relevant.

Changes in EPS samples were the most apparent (Table III). The most significant difference $(8.66 \%$ and $8.19 \%$ ) was found in configuration Types $9-12$ due to the twosided nano-ceramic coating. In case Types $1-4$ change level was higher $(5.82 \%$ and $5.75 \%)$ than in case of Types $5-8(4.75 \%$ and $4.96 \%)$. This phenomenon can be explained that if an air gap is closed inside two layers of thermal insulation air particles are less able to move and the effect of surface heat transfer resistance becomes smaller. There was no difference between measurement results depending on the location of the coating (warm or cold side).

Table III

Results of Experiment 3 with EPS samples

\begin{tabular}{|c|c|c|c|c|c|c|c|c|c|}
\hline \multicolumn{8}{|c|}{ Order of layers } & \multicolumn{2}{|c|}{$\begin{array}{c}\text { Thermal } \\
\text { conductivity }\end{array}$} \\
\hline $\begin{array}{c}\mathrm{AG} \\
(\mathrm{mm})\end{array}$ & $\begin{array}{l}\mathrm{NCC} \\
(\mathrm{mm})\end{array}$ & $\begin{array}{c}\text { EPS } \\
(\mathrm{mm})\end{array}$ & $\begin{array}{l}\mathrm{NCC} \\
(\mathrm{mm})\end{array}$ & $\begin{array}{c}\mathrm{AG} \\
(\mathrm{mm})\end{array}$ & $\begin{array}{l}\text { EPS } \\
(\mathrm{mm})\end{array}$ & $\begin{array}{l}\mathrm{NCC} \\
(\mathrm{mm})\end{array}$ & $\begin{array}{c}\mathrm{AG} \\
(\mathrm{mm})\end{array}$ & $\begin{array}{c}\lambda_{\text {eff }} \\
(\mathrm{W} / \mathrm{mK})\end{array}$ & $\begin{array}{c}\Delta \lambda_{\text {eff }} \\
(\%)\end{array}$ \\
\hline- & - & 20 & - & 20 & - & - & - & 0.06702 & $-582 \%$ \\
\hline - & - & 20 & 2 & 20 & - & - & - & 0.06312 & \\
\hline- & - & 20 & - & 30 & - & - & - & 0.08272 & 5750 \\
\hline- & - & 20 & 2 & 30 & - & - & - & 0.07796 & $-5.15 \%$ \\
\hline - & - & 20 & - & 20 & 20 & - & - & 0.05469 & \\
\hline - & - & 20 & 2 & 20 & 20 & - & - & 0.05209 & $-4.75 \%$ \\
\hline - & - & 20 & - & 30 & 20 & - & - & 0.06211 & \\
\hline - & - & 20 & 2 & 30 & 20 & - & - & 0.05903 & $-4.90 \%$ \\
\hline 20 & - & 20 & - & - & - & - & 20 & 0.08583 & 8660 \\
\hline 20 & 2 & 20 & - & - & - & 2 & 20 & 0.07840 & $-8.00 \%$ \\
\hline 30 & - & 20 & - & - & - & - & 30 & 0.10923 & \\
\hline 30 & 2 & 20 & - & - & - & 2 & 30 & 0.10028 & \\
\hline
\end{tabular}

In case of XPS samples smaller changes can be observed (Table IV). This could be explained by the results of Experiment 1 where nano-ceramic coating itself had resulted reduction of thermal conductivity. This is why surface heat transfer resistance seems to have minor effect on thermal insulation quality. Change of thermal conductivity was the most significant in configuration Types 1-4 (4.10\% and 3.36\%). Just like EPS samples, a little bit lower changes were measured in case of Types 5-8 (3.45\% and 3.36\%). There was also no difference between measurement results depending on the location of the coating (warm or cold side). In contrast to EPS samples configuration types 9-12 showed the lowest change in thermal conductivity.

In case of OSB boards insulating effect of nano-ceramic coating was undetectable (Table V). All measurements showed that coating has a negative effect on thermal insulation quality. Probably, not the same material quality and composition is suitable for all building structures and materials. Every time we need to find correct solution and the same material is not suitable for all surfaces. Presumably, insulating OSB plates 
needs different material quality, composition or application technology than EPS and XPS plates to achieve significant insulating effect.

\section{Table IV}

Results of Experiment 3 with XPS samples

\begin{tabular}{|c|c|c|c|c|c|c|c|c|c|}
\hline \multicolumn{8}{|c|}{ Order of layers } & \multicolumn{2}{|c|}{$\begin{array}{c}\text { Thermal } \\
\text { conductivity }\end{array}$} \\
\hline $\begin{array}{c}\mathrm{AG} \\
(\mathrm{mm})\end{array}$ & $\begin{array}{l}\text { NCC } \\
(\mathrm{mm})\end{array}$ & $\begin{array}{l}\mathrm{XPS} \\
(\mathrm{mm})\end{array}$ & $\begin{array}{l}\text { NCC } \\
(\mathrm{mm})\end{array}$ & $\begin{array}{c}\text { AG } \\
(\mathrm{mm})\end{array}$ & $\begin{array}{c}\text { EPS } \\
(\mathrm{mm})\end{array}$ & $\begin{array}{l}\text { NCC } \\
(\mathrm{mm})\end{array}$ & $\begin{array}{c}\text { AG } \\
(\mathrm{mm})\end{array}$ & $\begin{array}{c}\lambda_{\text {eff }} \\
(\mathrm{W} / \mathrm{mK})\end{array}$ & $\begin{array}{l}\Delta \lambda_{\text {eff }} \\
(\%)\end{array}$ \\
\hline- & - & 30 & - & 20 & - & - & - & 0.05144 & $-4.10 \%$ \\
\hline $\begin{array}{l}- \\
-\end{array}$ & $\begin{array}{l}- \\
-\end{array}$ & $\begin{array}{l}30 \\
30\end{array}$ & $\overline{2}$ & $\begin{array}{l}30 \\
30\end{array}$ & $\begin{array}{l}- \\
-\end{array}$ & $\begin{array}{l}- \\
-\end{array}$ & $\begin{array}{l}- \\
-\end{array}$ & $\begin{array}{l}0.06220 \\
0.06011\end{array}$ & $-3.36 \%$ \\
\hline $\begin{array}{l}- \\
-\end{array}$ & $\begin{array}{l}- \\
-\end{array}$ & $\begin{array}{l}30 \\
30\end{array}$ & $\overline{2}$ & $\begin{array}{l}20 \\
20\end{array}$ & $\begin{array}{l}20 \\
20\end{array}$ & $\begin{array}{l}- \\
-\end{array}$ & $\begin{array}{l}- \\
-\end{array}$ & $\begin{array}{l}0.04556 \\
0.04399\end{array}$ & $-3.45 \%$ \\
\hline $\begin{array}{l}- \\
-\end{array}$ & $\begin{array}{l}- \\
-\end{array}$ & $\begin{array}{l}30 \\
30\end{array}$ & $\overline{2}$ & $\begin{array}{l}30 \\
30\end{array}$ & $\begin{array}{l}20 \\
20\end{array}$ & $\begin{array}{l}- \\
-\end{array}$ & $\begin{array}{l}- \\
-\end{array}$ & $\begin{array}{l}0.05092 \\
0.04921\end{array}$ & $-3.36 \%$ \\
\hline $\begin{array}{l}20 \\
20\end{array}$ & $\overline{2}$ & $\begin{array}{l}30 \\
30\end{array}$ & $\begin{array}{l}- \\
-\end{array}$ & $\begin{array}{l}- \\
-\end{array}$ & $\begin{array}{l}- \\
-\end{array}$ & $\overline{2}$ & $\begin{array}{l}20 \\
20\end{array}$ & $\begin{array}{l}0.06456 \\
0.06276\end{array}$ & $-2.79 \%$ \\
\hline $\begin{array}{l}30 \\
30\end{array}$ & $\overline{2}$ & $\begin{array}{l}30 \\
30\end{array}$ & $\begin{array}{l}- \\
-\end{array}$ & $\begin{array}{l}- \\
-\end{array}$ & $\begin{array}{l}- \\
-\end{array}$ & - & $\begin{array}{l}30 \\
30\end{array}$ & $\begin{array}{l}0.08259 \\
0.08033\end{array}$ & $-2.74 \%$ \\
\hline
\end{tabular}

Table V

Results of Experiment 3 with OSB plates

\begin{tabular}{|c|c|c|c|c|c|c|c|c|c|}
\hline \multicolumn{8}{|c|}{ Order of layers } & \multicolumn{2}{|c|}{$\begin{array}{c}\text { Thermal } \\
\text { conductivity }\end{array}$} \\
\hline $\begin{array}{c}\mathrm{AG} \\
(\mathrm{mm})\end{array}$ & $\begin{array}{l}\mathrm{NCC} \\
(\mathrm{mm})\end{array}$ & $\begin{array}{l}\text { OSB } \\
(\mathrm{mm})\end{array}$ & $\begin{array}{l}\mathrm{NCC} \\
(\mathrm{mm})\end{array}$ & $\begin{array}{c}\mathrm{AG} \\
(\mathrm{mm})\end{array}$ & $\begin{array}{l}\text { EPS } \\
(\mathrm{mm})\end{array}$ & $\begin{array}{l}\mathrm{NCC} \\
(\mathrm{mm})\end{array}$ & $\begin{array}{c}\mathrm{AG} \\
(\mathrm{mm})\end{array}$ & $\begin{array}{c}\lambda_{\text {eff }} \\
(\mathrm{W} / \mathrm{mK})\end{array}$ & $\begin{array}{c}\Delta \lambda_{\text {eff }} \\
(\%)\end{array}$ \\
\hline- & - & 22 & - & 20 & - & - & - & 0.10630 & $+322 \%$ \\
\hline - & - & 22 & 2 & 20 & - & - & - & 0.10972 & $+3.22 \%$ \\
\hline- & - & 22 & - & 30 & - & - & - & 0.12660 & $+2370 \%$ \\
\hline - & - & 22 & 2 & 30 & - & - & - & 0.12960 & $+2.51 \%$ \\
\hline- & - & 22 & - & 20 & 20 & - & - & 0.06810 & \\
\hline - & - & 22 & 2 & 20 & 20 & - & - & 0.07003 & $+2.83 \%$ \\
\hline- & - & 22 & - & 30 & 20 & - & - & 0.07552 & 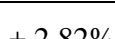 \\
\hline- & - & 22 & 2 & 30 & 20 & - & - & 0.07765 & $+2.82 \%$ \\
\hline 20 & - & 22 & - & - & - & - & 20 & 0.15097 & +1210 \\
\hline 20 & 2 & 22 & - & - & - & 2 & 20 & 0.15280 & $+1.21 \%$ \\
\hline 30 & - & 22 & - & - & - & - & 30 & 0.11800 & \\
\hline 30 & 2 & 22 & - & - & - & 2 & 30 & 0.12070 & \\
\hline
\end{tabular}

\section{Conclusions}

Laboratory tests showed that nano-ceramic thermal insulation coatings do not have an extremely low thermal conductivity that was described by the available documents of producers and distributors. Their thermal conductivity is likely to be higher than that of 
traditional thermal insulation materials like mineral wool products or plastic foams (e.g. EPS, XPS and polyurethane foam).

It seems to be proven that their insulating effect comes from a relatively high surface heat transfer resistance. However, it can be seen that insulating effect was much lower than previously expected. Test results also showed that the same material quality, composition and application technology may not be suitable for insulating different kind of surfaces.

Further studies are needed to confirm insulation effect of nano-ceramic thermal insulation coatings. There are running experiments in the Laboratory of Building Physics and Building Construction at Széchenyi István University (Györ, Hungary) with new types of configurations containing 200x200 mm air gap with a thickness of 20-30 and $60 \mathrm{~mm}$. Presumably in a larger air gap air particles should have more possibility for bulk movements. Thereby surface heat transfer resistance can prevail much better and higher differences may arise between coated and uncoated samples. Results will be reported in a subsequent study.

\section{References}

[1] Leydecker S. Nano-materials in architecture, interior architecture and design, Birkhäuser Verlag AG, Berlin, Germany, 2008.

[2] Kelsall R. W., Hamley I. W., Geoghegan M. Nanoscale science and technology, John Wiley \& Sons Ltd, Chichester, United Kingdom, 2005.

[3] Pacheco-Torgal F., Jalali S. Nanotechnology: Advantages and drawbacks in the field of construction and building materials, Construction and Building Materials, Vol. 25, No. 2, 2011, pp. 582-590.

[4] McIntyre R. A. Common nano-materials and their use in real world applications, Science Progress, Vol. 95, No. 1, 2012, pp. 1-22.

[5] Jablan S., Radovič L., Sazdanovič R. Knots and links in architecture, Pollack Periodica, Vol. 7, Suppl, 2012, pp. 65-76.

[6] Lan W., Kexing F., Liang Y., Botao W. The application of ceramic coatings in petroleum chemical and building industries, International Conference on Material and Environmental Engineering, Jiujiang, Jiangxi, China, 21-24 March 2014, Atlantis Press, pp. 146-149.

[7] Abdelrahman M. Towards sustainable architecture with nanotechnology, Al-Azhar Engineering 11th International Conference, Cairo, Egypt, 21-23 December, 2010, paper 154.

[8] Orbán J. Use of nanotechnology in building industry, Part I. (in Hungarian), Magyar Építéstechnika, No. 1, 2012, pp. 40-43.

[9] Orbán J. Use of nanotechnology in building industry, Part II. (in Hungarian), Magyar Épitéstechnika, No. 2-3, 2012, pp. 54-57.

[10] Vajda J., Perjési-Hámori I. Two dimensional mathematical model of heat-transmission in building structures, Pollack Periodica, Vol. 2, No. 3, 2007, pp. 25-34.

[11] Fullisol Ltd. TSM ceramics thermal insulation coatings (in Hungarian), Fullisol Ltd., Budapest, Hungary, p. 10, http://www.fullisol.hu/files/TSM $\% 20 \mathrm{Ker} \% \mathrm{C} 3 \% \mathrm{~A} 1 \mathrm{mia} \%$ 20bevonat_prospektus_v2.pdf (last visited 8 October 2014).

[12] Mart Ltd. New generation thermal insulating nano-coating with micro-sized ceramic balls, Mart Ltd., Dunakeszi, Hungary, p. 8. http://www.mahlmart.hu/docs/pages/mahlmart-prosieng.pdf, (last visited 12 December 2014). 
[13] Thermo-Shield Inc. Exterior wall coats, SPM Thermo-Shield Inc., Naples, Florida, United States, http://www.thermoshield.com/index.html/thermoshieldexteriorwall.html, (last visited 5 May 2015).

[14] MANTI Ltd. Nano-ceramic thermal protection (in Hungarian), MANTI Ltd, Budaörs, Hungary, http://ujsagos-stand.hu/media/muszerautomatika/manti/muszerautomatika.html (last visited 5 May 2015).

[15] Orbán J. Reducing energy consumption of buildings with the help of thin heat protection coatings, Part II (in Hungarian), Magyar Építéstechnika, No. 9, 2015, pp. 40-42.

[16] Hoffman D., Roy R., Komarneni S. Diphasic ceramic composites via a sol-gel method, Materials Letters, Vol. 2, No. 3, 1984, pp. 245-247.

[17] Paul G., Chopkar M., Manna I., Das P. K. Techniques for measuring the thermal conductivity of nano-fluids, A Review, Renewable and Sustainable Energy Reviews, Vol. 14, No. 7, 2010, pp. 1913-1924.

[18] Koniorczyk P., Zmywaczyk J., Kowalski M. Experimental studies of thermal conductivity of the composite coating consisted of hollow ceramic microspheres, In: Walczok W. (Ed.) 1st Scientific International Coating Congress, Berlin, Germany, 4-5 November 2004, p. 15.

[19] Lakatos Á., Csáky I., Kalmár F. Thermal conductivity measurements with different methods: a procedure for the estimation of the retardation, Materials and Structures, Vol. 48, No. 5, 2015, pp. 1343-1353.

[20] Nagy B. Laboratory measurements of construction materials for dynamic heat and moisture transport modelling (in Hungarian), In: S. Bodzás (Ed.) Müszaki Tudomány az Észak-Kelet Magyarországi Régióban 2015, Debrecen, Hungary, Technical Committee of Debrecen Academic Committee 2015, pp. 446-452.

[21] Čekon M. Thermodynamic properties of reflective coatings, Advanced Materials Research, Vol. 649, 2013, pp. 179-182.

[22] Čekon M., Kalousek M., Hraška J., Ingeli R. Spectral optical properties and thermodynamic performance of reflective coatings in a mild climate zone, Energy and Buildings, Vol. 77, 2014, pp. 343-354.

[23] Čekon M. Spectral emissivity properties of reflective coatings, Slovak Journal of Civil Engineering, Vol. 20, No. 2, 2012, pp. 1-7.

[24] Bozsaky D. Laboratory test with liquid nano-ceramic thermal insulation coating, Procedia Engineering, Vol. 123, 2015, pp. 68-75.

[25] Bozsaky D. Thermal insulation with nanotechnology-based materials, In: H. Bruckner (Ed.) Internationales Symposium Eventmaterials, TU Wien, Wien, Austria, 19-20 November, 2015, pp. 137-154.

[26] Pavlík Z., Jerman M., Trník A., Kočí V., Černý R. Effective thermal conductivity of hollow bricks with cavities filled by air and expanded polystyrene, Journal of Building Physics, Vol. 37, No. 4, 2014, pp. 436-448. 